\title{
Neurology of ciguatera
}

\author{
J Pearn
}

\begin{abstract}
Ciguatera is a widespread ichthyosarcotoxaemia with dramatic and clinically important neurological features. This severe form of fish poisoning may present with either acute or chronic intoxication syndromes and constitutes a global health problem. Ciguatera poisoning is little known in temperate countries as a potentially global problem associated with human ingestion of large carnivorous fish that harbour the bioaccumulated ciguatoxins of the photosynthetic dinoflagellate Gambierdiscus toxicus. This neurotoxin is stored in the viscera of fish that have eaten the dinoflagellate and concentrated it upwards throughout the food chain towards progressively larger species, including humans. Ciguatoxin accumulates in all fish tissues, especially the liver and viscera, of "at risk" species. Both Pacific (P-CTX-1) and Caribbean (C-CTX-1) ciguatoxins are heat stable polyether toxins and pose a health risk at concentrations above $0.1 \mathrm{ppb}$. The presenting signs of ciguatera are primarily neurotoxic in more than $80 \%$ of cases. Such include the pathognomonic features of postingestion paraesthesiae, dysaesthesiae, and heightened nociperception. Other sensory abnormalities include the subjective features of metallic taste, pruritis, arthralgia, myalgia, and dental pain. Cerebellar dysfunction, sometimes diphasic, and weakness due to both neuropathy and polymyositis may be encountered. Autonomic dysfunction leads to hypotension, bradycardia, and hypersalivation in severe cases. Ciguatoxins are potent, lipophilic sodium channel activator toxins which bind to the voltage sensitive (site 5) sodium channel on the cell membranes of all excitable tissues. Treatment depends on early diagnosis and the early administration of intravenous mannitol. The early identification of the neurological features in sentinel patients has the potential to reduce the number of secondary cases in cluster outbreaks.

(F Neurol Neurosurg Psychiatry 2001;70:4-8)
\end{abstract}

Keywords: ciguatera; fish poisoning; neurotoxins; public health
It was Galen who first said that Moray eels were dangerous to eat. ${ }^{1}$ When European colonists first settled in the islands of the Caribbean they encountered the neurological consequences suffered by gourmet victims who had ingested the local gastropod, Livona, called "cigua". It was thought that all cases were due to the ingestion of snails, although it is now appreciated that most were in fact due to the eating of ciguatoxic fish. Parra, in 1787 in his "Description de Diferents Piezas" in the Antilles, referred to the neurological symptoms of the clinical intoxication which he called "siguatera". ${ }^{1}$

The neurological manifestations of ciguatera are dramatic and often enigmatic. Ciguatoxins are some of the most potent biological toxins known. Their neurotropic effects produce a protean array of symptoms which are distressing in the acute phase syndrome and which are enervating throughout the often prolonged progression of convalescence.

The detailed neurological effects of ciguatera were first described by Surgeon Lieutenant William Anderson RN, naval surgeon on Cook's Ship HMS Resolution, in the Pacific in $1786 .{ }^{2}$ Cook's crew had caught fish which were eagerly eaten by the sailors and the scraps fed to the ship's dogs. Anderson described the neurological features of the consequent severe intoxication in both human and canine victims. He described the distressing skin tingling, the "reversal" of tactile heat sensation, and the accompanying nausea and prostration.

Ciguatera is a clinical intoxication ${ }^{3-5}$ caused by the ingestion of ciguatoxic fish. ${ }^{6}$ Human victims are the end link in a food chain cascade. ${ }^{7}$ The primary toxins are manufactured in the benthic (bottom dwelling) dinoflagellate Gambierdiscus toxicus; ${ }^{3}$; ; and are concentrated successively in the flesh and viscera of small piscine herbivores, small carnivorous fish, and ultimately in larger fish, many species of which are prized gourmet species. "At risk" fish include some species of mackerel (Scomberomorus $s p$ ) and barracuda (Sphyraena $s p)^{3}$ and many of the tropical reef species such as coral trout (Plectropomus $s p)^{5}$; and in some parts of the world include the flesh and viscera of Moray eels (Lycodontis $s p$ ). ${ }^{8}$ The disease is not uncommon in many littoral populations of the tropical and subtropical nations of the world. ${ }^{9}$ In some island nations in the Caribbean and in the Pacific where the principal source of protein is fish, the annual incidence of 
intoxication may approach $10 \%$ of the population. ${ }^{10}$ Ciguatera poisoning is poorly understood as a potential global health problem in temperate countries, particularly in North America and Europe. The toxin is stored in the viscera of fish that have eaten the photosynthetic dinoflagellate; and is progressively concentrated upwards along the food chain. The toxin is stable in the tissue of living fish and does them no harm. Larger carnivores have higher concentrations of the toxin in their tissues. The practical consequence of this is that consumption of the largest carnivorous fish-often those gourmet specimens which are frozen and transported for intercontinental consumption - therefore forms the greatest risk of ciguatera intoxication for the consumer. Pacific ciguatoxins pose a health risk at concentrations (within ingested fish flesh) above 0.1 ppb. $^{11}$

Extensive international commerce in frozen fish, and especially that involving trade in gourmet reef species, means that victims of this dramatic intoxication may now be encountered in all countries. ${ }^{12}$ An estimated $10000-50000$ victims have the disease annually. ${ }^{13}$ Cases have been reported in the past decade from the United States (Hawaii ${ }^{14}$ and from Rhode Island $^{15}$ ), Madagascar, ${ }^{16}$ Hong Kong, ${ }^{17}$ Europe, ${ }^{12}$ and extensively from the South $\mathrm{Pa}$ cific. ${ }^{349}$ Ciguatera is thus a global health problem from the perspective of preventive medicine $e^{5}$ and an acute challenge for the clinician treating individual cases.

Increased awareness of the neurotoxic effects of ciguatera will aid in earlier diagnosis. ${ }^{3}$ This in turn will facilitate earlier treatment ${ }^{18}$ and the shortening of convalescence. The earlier identification of sentinel patients has the potential to prevent secondary cases and thus reduce the clinical clusters or microepidemics of victims.

\section{Ciguatoxins}

Ciguatoxins are potent heat stable, nonprotein, lipophilic sodium channel activator toxins that bind quasi-irreversibly to the voltage sensitive sodium channel at site five. ${ }^{19}$ The molecular targets are found on all membranes of excitable tissues but with varying tissue specific affinity. The receptor site overlaps the receptor site for brevitoxin, another food chain paralytic toxin. ${ }^{20}$ Both Pacific and Caribbean ciguatoxin ${ }^{8}$ have as their basic structure unique molecular chains of 13 and 14 joined ether rings $\left(\mathrm{c}_{62} \mathrm{H}_{92} \mathrm{O}_{19}\right)$ respectively. Nine of these transfused rings form a ladder which is very similar in all ciguatoxins (figure). ${ }^{118}$ The toxins are tasteless and odourless and are relatively heat stable to the temperatures usually employed in cooking. Both Pacific ciguatoxins (P-CTX-1) and Caribbean ciguatoxins (C-CTX-1) are stable for at least 6 months at commercial freezing temperatures. ${ }^{19}$

Clinical evidence suggests that the toxin binds to sodium channel receptor sites of both somatic and autonomic nerves. The chronicity of symptoms (months or years in some victims $)^{21} 22$ and the exquisite sensitivity of convalescent victims accidentally subjected to rechallenge ${ }^{418}$ suggests that the sodium channel receptors are inactivated permanently; and that convalescence from severe intoxication may depend on the generation of new receptors.

Extensive experimental studies of Pacific ciguatoxins, using rat dissociated dorsal root ganglion neurons in whole cell patch clamp techniques, have shown that P-CTX-1 causes tetrodotoxin sensitive (TTX-S) sodium channels to open closer to their normal resting membrane potential. By contrast, tetrodotoxin resistant (TTX-R) sodium channels recover from inactivation more quickly, enabling earlier

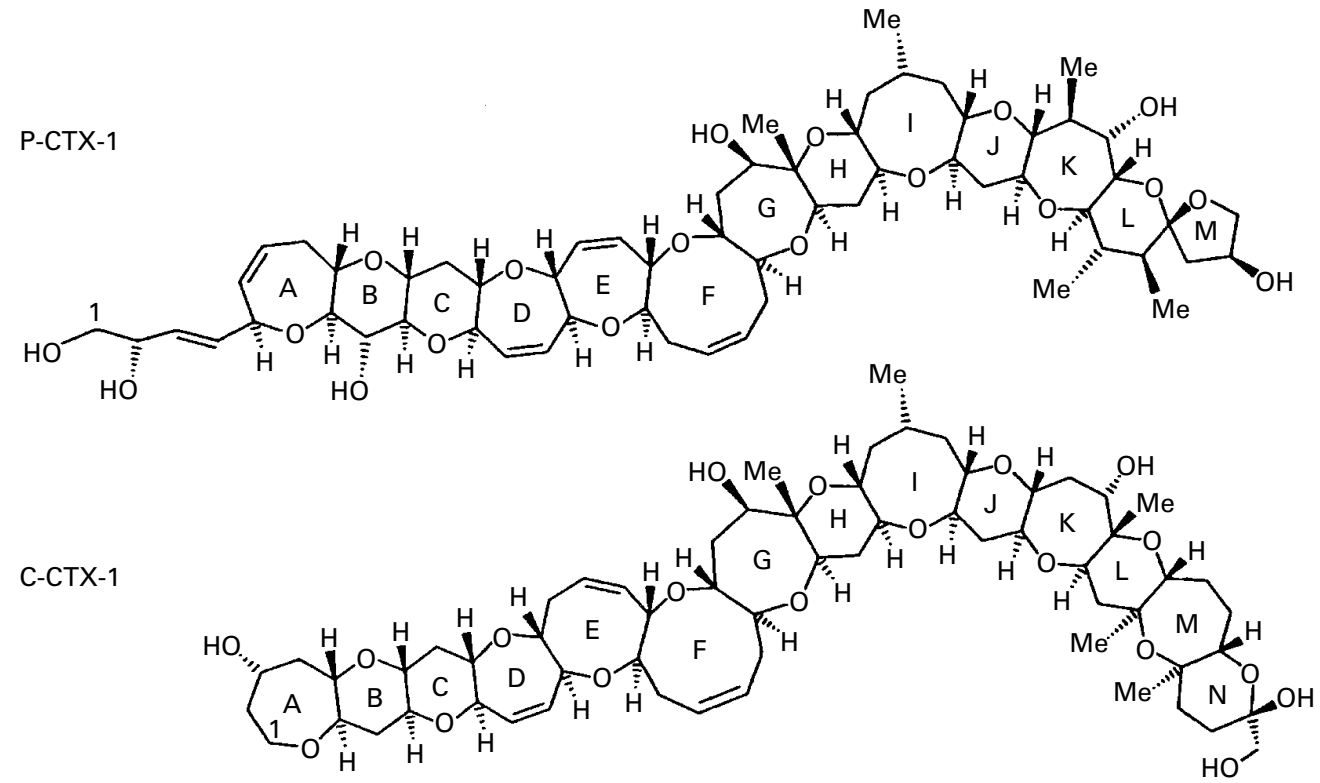

Molecular structure of the Pacific (P-CTX-1) and the Caribbean $(C-C T X-1)$ ciguatoxins. These toxins are heat stable polyether molecules of 1023-1157 Da and post a health risk at concentrations above 0.1 ppb. Structure courtesy of Associate Professor Richard Lewis, University of Queensland, with acknowledgements. 
transition to the open state. ${ }^{23}$ The CTX induced effects are resistant to sustained (20-30 minutes) washout with external solution, a phenomenon seen in phrenic hemidiaphragm nerve-muscle preparations. ${ }^{24}$ These properties, combined with a high lipid solubility of the toxin and its long known retention in the neuronal membranes, ${ }^{25}$ explain, at least in part, the chronic nature of the neurological symptoms. In particular, such experiments provide a basis for understanding the pathogenesis of sensory neurological disturbances caused by ciguatoxic fish poisoning.

\section{Acute ciguatera: neurological symptoms and signs}

The full syndrome of ciguatera involves neurological, musculoskeletal, dermatological, gastrointestinal, and psychological symptoms. ${ }^{3-}$ 5926 The neurological symptoms, subjectively always the most distressing, are listed in the table.

Neurological features may include peripheral sensory or motor symptoms, central symptoms such as severe prolonged distressing headache ${ }^{27}{ }^{28}$ or autonomic features. ${ }^{27}$ In severe intoxications, autonomic dysfunction may present as bradycardia or hypotension.

Mortality is region specific, and in the case of the Pacific ciguatoxins is less than $0.5 \% .^{27}$ The pathognomonic symptoms of acute ciguatera poisoning are paraesthesiae and dysaesthesiae. The paraesthesiae spread centrifugally, dependent on ingested dose, from circumoral origins. The pathophysiological basis for the centrifugal spread of symptoms has not been determined. It has been proposed informally that this may be due to a disproportionate concentration of sodium channel receptors along the peripheral nerves; or may be due to a primary neurotoxic selectivity acting on the cell bodies of sensory nerves initially with subsequent intraneural spread of the toxin along both axons and dendrites. Several hours after consuming a fish meal, victims awake at night, perplexed and distressed. The paraesthesiae last for a minimum of several days and in severe cases persist for many weeks. The slow regression of such paraesthesiae often causes secondary anxiety or depressive symptoms. In my experience these secondary symptoms may be accentuated in victims who have been severely poisoned in miniepidemics; and who see themselves chronically ill by contrast and comparison with those who were mildly affected and who recovered from their perplexing symptoms within a few days of initial poisoning.

Ciguatoxic dysaesthesia is classically referred to as a "reversal of thermal sensation". The best modern description of this pathognomonic symptom was that given by Bagnis who highlighted this feature in the Bulletin of the World Health Organisation in 1970 as a "paradoxical sensory disturbance". ${ }^{29}$ The clinical features of ciguatera intoxication were the further subject of a detailed study in the United States Virgin Islands by Morris et al in $1982 .^{32}$ In my experience the dysaesthesia of ciguatera is not a true reversal of thermal sensation. Rather, cold or even room temperature objects, when touched, produce a disagreeable burning sensation; and warm objects produce a sensation described variously by victims in such terms as "ice burning cold", "chilled", or "cold-sharp". Warm fluids are particularly distressing and showering or bathing may be too painful to endure by some severely poisoned victims. I have seen adult cases with such heightened nociperception, especially to fluids, that victims are reduced to shocked weeping in the context of unbearable distress during micturition or breast feeding. Cerebellar signs and a late presenting tremor ${ }^{30} 31$ are well described in the unpublished reports of victim support associations. Because these cerebellar signs may appear after the subsidence of paraesthesiae and are themselves self limiting, they have not been reported in detail.

\section{Chronic ciguatera: neurological features}

The chronic effects of ciguatera have been recognised in Pacific littoral communities for centuries. Studies in the United States Virgin Islands showed that more than half of the victims poisoned by Caribbean ciguatoxins had chronic dysaesthesia with a median duration exceeding 2 weeks after initial poisoning. ${ }^{32}$

The intractable fatigue, experienced by some $3 \%-20 \%$ of severely intoxicated victims, is perplexing to patients and frustrating to doctors. The persistent fatigability and weakness ${ }^{21} 22$ is often accompanied by depression. It is not known whether the depression-which in some victims can be a major feature of the prostrating fatigability of chronic ciguatera-is due primarily to residual toxic effects, or secondary to the organic debilitation which may follow the primary episode of poisoning. In patients presenting with the constellation of symptoms

Table 1 Acute neurological symptoms and signs seen by ciguatera victims

\begin{tabular}{|c|c|}
\hline Symptom & Notes \\
\hline Paraesthesiae $^{34}$ & $\begin{array}{l}\text { One of the first signs of ciguatera intoxication. }{ }^{37} \text { Occurs within hours of toxic fish ingestion. } \\
\text { Symptoms last for days or weeks. Centrifugal spread from circumoral and glossal focus. }\end{array}$ \\
\hline Dysaesthesiae $^{3426}$ & $\begin{array}{l}\text { A combination of hyperaesthesia; heightened nociperception; peripheral dysaesthesiae with } \\
\text { possible central element of perverted sensation. }\end{array}$ \\
\hline Other sensory signs & Metallic taste ${ }^{37}$ pruritus, ${ }^{40}$ arthralgia, and myalgia. \\
\hline Pain & Limb, ${ }^{3}$ skin, joints, ${ }^{3}$ dental, ${ }^{26}{ }^{37}$ and urethral. ${ }^{18}$ \\
\hline Headache $^{3410}$ & May be a presenting sign. Usually non-localised; may be intense and prolonged. \\
\hline Weakness $^{310}$ & Both peripherial features often with central accentuation due to prostration. \\
\hline Autonomic signs & Hypersalivation, bradycardia, laryngeal spasm, hypotension, mydriasis, or meiosis. \\
\hline Sensory signs ${ }^{18} 27$ & Insomnia, vertigo, nightmares (especially zoopsia ${ }^{40}$ ), coma, ${ }^{15}$ convulsions. \\
\hline Motor symptoms and signs ${ }^{27}$ & Weakness ${ }^{16}$ (due to both neural involvement ${ }^{34}$ ) and polymyositis, ${ }^{35}{ }^{36}$ hyporeflexia; dysphagia, paresis. \\
\hline Cerebellar signs and tremor & Sometimes late presenting; may occur up to 10 days after initial intoxication. ${ }^{3031}$ \\
\hline
\end{tabular}


and signs which comprise the chronic fatigue syndrome ${ }^{33}$ it is always important to include the possibility of chronic ciguatera in the differential diagnosis. ${ }^{22}$ In rare cases ciguatera may cause peripheral neuropathy and polymyositis. $^{34-36}$

The insomnia of the acute ciguatera syndrome may gradually change into the hypersomnolence which is a common feature of chronic ciguatera, and is cognate to that experienced by victims of chronic fatigue syndrome. In cases of chronic fatigue syndrome in which ciguatera can confidently be established as the cause, there is no need-indeed it is counterproductive - to embark on open ended extensive investigations and a continuum of pathological tests. A milieu of optimism, with confidence about the success of long term convalescence, is the best approach during long term clinical surveillance of such victims over ensuing months.

\section{Differential diagnosis}

The ichthyosarcotoxaemias include maitotoxaemia, fugu (tetrodotoxin poisoning), scombroid (histamine) fish poisoning, clupeoid poisoning, ${ }^{37}$ elasmobranch (shark liver) poisoning, mercury fish poisoning, and bacterial fish despoilment. None has the peculiar dramatic features of dysaesthesiae so characteristic in some $80 \%$ of victims of ciguatera. Fugu may produce rapid onset paraesthesiae and a generalised numbness with the subjects describing a feeling of "floating on air" - a transient state which may progress to life threatening acute paralysis. Clupeoid poisoning may follow the eating of herring-like fish and presents with abdominal pain, itching, coma, and convulsions. Scombroid poisoning (histamine poisoning) may follow the eating of spoiled tuna, bonito, mackerel, and skipjack. Scombroid or histamine fish poisoning is now the most prevalent form of seafood borne disease in the United States. Histamine production in these stored fish is a consequence of the free histidine content of the fresh fish which is broken down by the bacterial enzyme histidine decarboxylase. The most common symptoms of scombroid poisoning include flushing, urticaria, hypotension, and headache - always associated with vomiting, diarrhoea, and abdominal cramps. Itching may be intense and be associated with urticarial lesions.

Currently there is no secure, commercially pragmatic test for ciguatoxins in fish flesh. The traditional method of detecting the presence of ciguatoxins in fish flesh involves testing lipid extracts by mouse bioassay. Recent research has shown that cytotoxicity, radioligand binding, and antibody based methods have the potential to be developed into cost effective screens for ciguatoxic fish at the market place or restaurant. ${ }^{11}$ The toxin is so potent that high performance liquid chromatography and mass spectroscopy are not sufficiently sensitive to detect clinically relevant concentrations of ciguatoxin in crude extracts of fish. ${ }^{11}$ Bioassays are available in various research centres. ${ }^{8}$ The diagnosis is essentially a clinical one, made particularly in the context of a detailed history of the type of fish species ingested, the rate of onset of symptoms, and a knowledge of the characteristic neurological features.

Nerve conduction studies may be abnormal. ${ }^{38}$ In experimental animals neurophysiological studies have demonstrated slowing of both mixed and motor nerve conduction velocities with reduction of depolarisation amplitudes. ${ }^{38}{ }^{39}$ It is important to appreciate that many toxins produce dysaesthesae as an important "sentinel" symptom of clinical poisoning. ${ }^{40} 41$ In the context of differential diagnosis, paraesthesia is a non-specific feature in itself; and the point should clearly be made that both sodium ion channel "openers" (for example, ciguatoxin, pyrethroids) and sodium ion channel "closers" (for example, tetrodotoxin and the clinical syndrome of fugu poisoning) produce similar, early onset "sentinel" circumoral distribution of paraesthesia.

\section{Treatment}

Hyperosmotic mannitol infusions ${ }^{18-22}$ may reduce Schwann cell oedema which is a feature of acute ciguatera. ${ }^{27}$ Although not yet tested by double blind trials, most case series report that more than $60 \%$ of victims have their symptoms reversed by mannitol infusion ${ }^{4} 91826$ provided that this is administered within 48 hours of the onset of symptoms. No other therapy, other than non-specific supportive management, has been shown to be of benefit. The neurological symptoms, however chronic, always resolve gradually. Some $5 \%$ of severely intoxicated victims complain of residual symptoms, particularly overwhelming chronic fatigue, for many months or even years after the acute episode.

Lipid storage and slow release of toxin has been proposed as the basis for the persistence and recurrent nature of the symptoms. Many victims report that relapses are triggered by other agents such as alcohol. However, it is known that relapse of symptoms may be initiated by the ingestion of chicken or pig meats from commercially raised animals which have been fed on fish meal; with the implication that such commercial feedstocks contain ciguatoxins in otherwise subclinical concentrations.

Intravenous mannitol infusion is the only therapy known to reverse the sensory symptoms and autonomic signs of ciguatera. The dose of mannitol which is recommended is 10 $\mathrm{ml} / \mathrm{kg}$ of the standard $20 \%$ solution, infused slowly over not less than 30-45 minutes. ${ }^{418}$ If dehydration has developed due to vomiting as part of the acute phase syndrome, this should be corrected before mannitol infusion is instituted. If symptoms are reduced, a second dose can be given within 3-4 hours; and repeated on the next day. The pharmacological basis for the use of mannitol remains speculative. ${ }^{18}$ Its effect is thought to be due to osmotic reduction of neuronal oedema, but a "scavenger" property of the molecule has been suggested. ${ }^{18}$ No ill effects have yet been reported from its use and I have not experienced ill effects from its use in personal unpublished cases. There is no accumulated 
evidence to suggest that the blood-brain barrier is opened to larger concentrations of ciguatoxin.

The pleomorphic nature of ciguatera, the subjectivity of many of its symptoms in the absence of any definitive laboratory diagnosis for clinical cases make this condition one of the most challenging in clinical medicine.

I thank Dr Christopher Gardner-Thorpe, Consultant Neurologist of Exeter; Associate Professor Richard Lewis of the Centre for Drug Design, the University of Queensland, Brisbane; and Emeritus Professor Peter Behan of the Institute of Neurological Sciences, University of Glasgow, for much encouragement.

1 Lee C. Fish poisoning with particular reference to ciguatera. f Trop Med Hyg 1980;83:93-7.

2 Pearn J. Around the rim: the role of surgeons in discovery and research in the Pacific rim. Part 1-surgeons in the Pacific: expeditions and expedition leaders. Aust NZ F Surg 1994;64:38-44.

3 Lewis R, Gillespie N, Pearn JH, et al. Ciguatera in Australia. Occurrence, clinical features, pathophysiology and management. Med f A Aust 1986;145:584-90.

4 Pearn JH. Ciguatera: dilemmas in clinical recognition, presentation and management. Mem Old Museum 1994;34: entation.

5 Lehane L. Ciguatera update. Med f Aust 2000;172:176-9.

6 Lewis RJ. Ciguatoxins are potent ichthyotoxins. Toxicon 1992;30:207-11.

7 Lewis RJ, Holmes MJ. Origin and transfer of toxins involved in ciguatera. Comp Biochem Physiol 1993;106:615-28.

8 Lewis RJ, Sellin M, Poli MA, et al. Purification and characterization of ciguatoxins from Moray eel (Lycodontis javanicus, Muraenidae). Toxicon 1991;29:1125-7.

9 Ting J, Brown AFT, Pearn JH. Ciguatera poisoning: clinical dilemmas and problems in differential diagnosis. Aust NZ Public Health 1998;22:140-2.

10 Lewis RJ, Ruff TA. Ciguatera: ecological, clinical and socioeconomic perspectives. Crit Rev Environ Sci Tech 1993;23: $137-56$.

11 Lewis RJ, Jones A, Vernoux J-P. HPLC-tandem electrospray mass spectrometry for the determination of sub-ppb levels fish. Anal Chem 1999;71:247-50.

12 Moulignier A, Binet D, Frottier J. Ciguatera fish poisoning: also in Europe. $\mathcal{F}$ Neurol Neurosurg Psychiatry 1995:59:192.

13 Brusle J. Ciguatera fish poisoning: a review. Sanitary and cconomic aspects. Paris: Les Editions INSERM, 1997.

14 Katz AR, Terrell-Perica S, Sasaki DM. Ciguatera or Kauai: investigation factors associated with severity of illness. $A m$ f Trop Med Hyg 1993;49:448-54

15 De Fusco DJ, O'Dowd P, Hokama Y, et al. Coma due to ciguatera poisoning in Rhode Island. Am f Med 1993;95: $240-3$

16 Habermehl GG, Krebs HC, Rasoanaivo P, et al. Severe ciguatera poisoning in Madagascar: a case report. Toxicon 1994:32:1539-42.

17 Leung KP, Chan TY, Sze FK. Ciguatera poisoning in Hong Kong: a report of two cases. Southeast Asian $\mathcal{F}$ Trop Med Public Health 1992;23:543-4.
18 Pearn JH, Lewis R, Ruff T, et al. Ciguatera and mannitol. Experience with a new treatment regimen. Med f Aust 989;151:77-80.

19 Lewis RJ, Vernoux J-P, Brereton IM. Structure of Caribbean ciguatoxin isolated from Caranx latus. F $\mathrm{Am}$ Chem Soc 1998;120:5914-20

20 Benoit E, Juzans P, Legrand A-M, et al. Ciguatoxins and brevitoxins. Neuroscience 1996;71:1121-31.

21 Pearn J. Ciguatera-a potent cause of the chronic fatigue syndrome. F Immunol Immunopharmacol 1995;15:63-5.

22 Pearn JH. The chronic fatigue syndrome-chronic ciguatera as part of the differential diagnosis. Med $\mathcal{F}$ Aust 1997;166: $309-10$

23 Strachan LC, Lewis RJ, Nicholson GM. Differential actions of pacific ciguatoxin-1 on sodium channel subtypes in mammalian sensory neurons. F Pharmacol Exp Therapeutics 999;288:379-88.

24 Lewis RJ, Wong Hoy AW. Comparative action of three major ciguatoxins on guinea-pig atria and ilea. Toxicon 1993;31: 437-46.

25 Scheuer PJ, Takahashi W, Tsutsumi J, et al. Ciguatoxin isolation and chemical nature. Science 1967;155:1267-8.

26 Karalis T, Gupta L, Chu M, et al. Three clusters of ciguatera poisoning: clinical manifestations and public health implications. Med F Aust 2000;172:160-2.

27 Allsop JL, Martini L, Lebris H, et al. Les manifestations neurologiques de la ciguatera. Rev Neurol (Paris) 1986;142: $590-7$.

28 Nakano KK. Ciguatera poisoning an outbreak on Midway Island. Clinical electrophysiological and muscle biopsy findings. I Neurology Orthopedic Surgery 1983;4:11-16.

29 Bagnis R, Bergland F, Elias PS, et al. Problems of intoxicants in marine food products. Bull World Health Organ 1970;42: 69-80.

30 Chungue E, Bagnis R, Fusetani N, et al. Isolation of two toxins from a parrot fish. Toxicon 1977;15:89-94.

31 Chungue E, Bagnis R, Yasumoto T. Le complexe toxinique des poissons perroquets. Biochimie 1977;59:739-43.

32 Morris JG, Lewin P, Hargrett NT, et al. Clinical features of ciguatera fish poisoning. Arch Intern Med 1982;142:10902.

33 Fukuda K, Strauss SE, Hickie, et al. The chronic fatigue syndome a comprehensive approach to case definition and study. Ann Intern Med 1994;121:953-9.

34 Cameron J, Flowers AE, Capra MF. Modifications of the peripheral nerve disturbance in ciguatera poisoning in rats with lidocaine. Muscle Nerve 1993;16:782-6.

35 Stommel EW, Parsonnet J, Jenkyn LR. Polymyositis after ciguatera exposure. Arch Neurol 1991;48:874-7.

36 Stommel EW, Jenkyn LR. Another case of polymyositis after ciguatera toxin exposure. Arch Neurol 1993;50:571.

37 Southcott RV. Marine toxins. In: PJ Vinken, GN Bruyn, eds. Handbook of clinical neurology. Vol 37. Part II. Amsterdam: North-Holland, 1979:78-106.

38 Cameron J, Flowers AE, Capra MF. Electrophysiological studies on ciguatera poisoning in man (part II). F Neurol Sci 1991;101:93-7.

39 Cameron J, Flowers AE, Capra MF. Effects of ciguatoxin on nerve excitability in rats (part 1). F Neurol Sci 1991;101:8792

40 Bagnis R. Fish poisoning in the South Pacific. Noumea, New Caledonia: South Pacific Commission, 1975:1-50.

41 Russell FE, Egen NB. Ciguateric fishes, ciguatoxin (CTX) and ciguatera poisoning. Fournal of Toxicology and Toxin Reviews 1991;10:37-62. 